\title{
DOCUMENTING MODERN MEXICAN ARCHITECTURAL HERITAGE FOR POSTERITY: BARRAGÁN'S CASA CRISTO, IN GUADALAJARA, MEXICO
}

\author{
Mezzino D., ${ }^{\mathrm{a}}$ Pei, W., ${ }^{\mathrm{a}}$ Santana Quintero, M., ${ }^{\mathrm{a}}$ Reyes Rodríguez, R. ${ }^{\mathrm{b}}$ \\ ${ }^{a}$ Carleton Immersive Media Studio (CIMS), 1125 Colonel by drive, Ottawa, On, K1S 5B6 Canada, davide.mezzino@gmail.com - \\ chloe.weiyipei@gmail.com - mario.santana@ carleton.ca \\ ${ }^{\mathrm{b}}$ Centro universitario de Arte Arquitectura y Diseño, Universidad de Guadalajara, Calzada Independencia Norte 5075, Huentitán El \\ Bajo, 44250, Guadalajara, Jalisco, Mexico, ramon.reyes@cuaad.udg.mx
}

\section{Commission VI, WG VI/4}

KEY WORDS: 3D Imaging, Recording, Photogrammetry, EDM, Computer-Aided Drawing, Rectified Photography, Conservation, Luis Barragán, Documentation, Modern Architecture.

\begin{abstract}
:
This contribution describes the results of an International workshop on documentation of historic and cultural heritage developed jointly between Universidad de Guadalajara's Centro Universitario de Arte, Arquitectura y Diseño (CUAAD) and Carleton University's Architectural Conservation and Sustainability Program. The objective of the workshop was to create a learning environment for emerging heritage professionals through the use of advanced recording techniques for the documentation of modern architectural heritage in Guadalajara, Mexico. The selected site was Casa Cristo, one of the several architectural projects by Luis Barragán in Guadalajara. The house was built between 1927 and 1929 for Gustavo R. Cristo, mayor of the city. The style of the building reflects the European influences derived from the architect's travel experience, as well as the close connection with local craftsmanship. All of these make the house an outstanding example of modern regional architecture. A systematic documentation strategy was developed for the site, using different survey equipment and techniques to capture the shape, colour, spatial configuration, and current conditions of Casa Cristo for its eventual rehabilitation and conservation.
\end{abstract}

\section{INTRODUCTION}

\subsection{Scope of work and training}

Conservation practice of modern architectural heritage has only been incremented in the last 25 years. In 2012, the Getty Conservation Institute (GCI) launched the Conserving Modern Architecture Initiative (CMAI) that defined the rules and methodologies to support the development of conservation practice of modern heritage (Normandin, Macdonald, 2013).

The documentation of the historic site of Casa Cristo by the architect Luis Barragán was undertaken by the students of Universidad de Guadalajara's Centro Universitario de Arte, Arquitectura y Diseño (CUAAD) and Carleton University's Architectural Conservation and Sustainability Program, under the supervision of professors of both universities. The purpose of the workshop aimed at developing a learning environment for emerging heritage professionals, through the use of advanced recording techniques, for the documentation of modern architectural heritage.

The documentation project consisted of several phases. The first one focused on the site analysis, considering the historical framework, geographical location and social significance of the site. The following phase involved the survey of the house using different techniques, including electronic distance meter (EDM), digital Photogrammetry and recording photography. The third phase concentrated on the processing of raw data obtained from the second phase. The resulting outputs laid the groundwork for developing the condition assessment of the house. At the final stage, recommendations for the eventual conservation and rehabilitation project were provided based on the results of the previous analysis.

The purpose of the work aimed at identifying the features of modern architecture, considering its construction methods and materials, the role of this building and its architectural style in the social framework and the integration of the tangible and intangible aspects in the conservation process, in agreement with the Article 1.1 of Approaches for the Conservation of Twentieth-Century Architectural Heritage, Madrid Document $2014{ }^{1}$. According to the purposes and objectives developed by GCI in the 2013 Colloquium to Advance the Practice of Conserving Modern Heritage, the works focus on:

- Identify and prioritize current needs;

- Identify potential actions to meet these needs;

- Develop a documentation strategy to be integrated in the conservation plan.

With respect to the current debate on modern heritage conservation, a 'customized' (Normandin, Macdonald, 2013) documentation strategy was designed to address different conservation issues, such as:

- Understanding the correlation between the building and the architect's productions;

\footnotetext{
${ }^{1}$ In 2014, the committee published a document: Approaches for the Conservation of Twentieth-Century Architectural Heritage. The document, also known as Madrid Document, based on the information presented during the $17^{\text {th }}$ ICOMOS General Assembly held in Madrid in 2011, provides international benchmark guidance about how to conserve and manage modern heritage.
} 
- Understanding and documenting the historical context, the architectural typology, as well as the character-defining elements;

- Recording the technical and social features of the building in addition to the aesthetic ones;

- Developing the education and training programs for the conservation of modern architecture.

\subsection{Luis Barrragán's architecture}

In order to understand Luis Barragán's architecture, it is necessary to understand the Art Deco Movement in Guadalajara. At the end of the Mexican Revolution, new styles were developed all over the country as a rejection of the previous architectural languages used by the old dictatorship regime of Porfirio Diaz (1876 - 1911) and by its social elite.
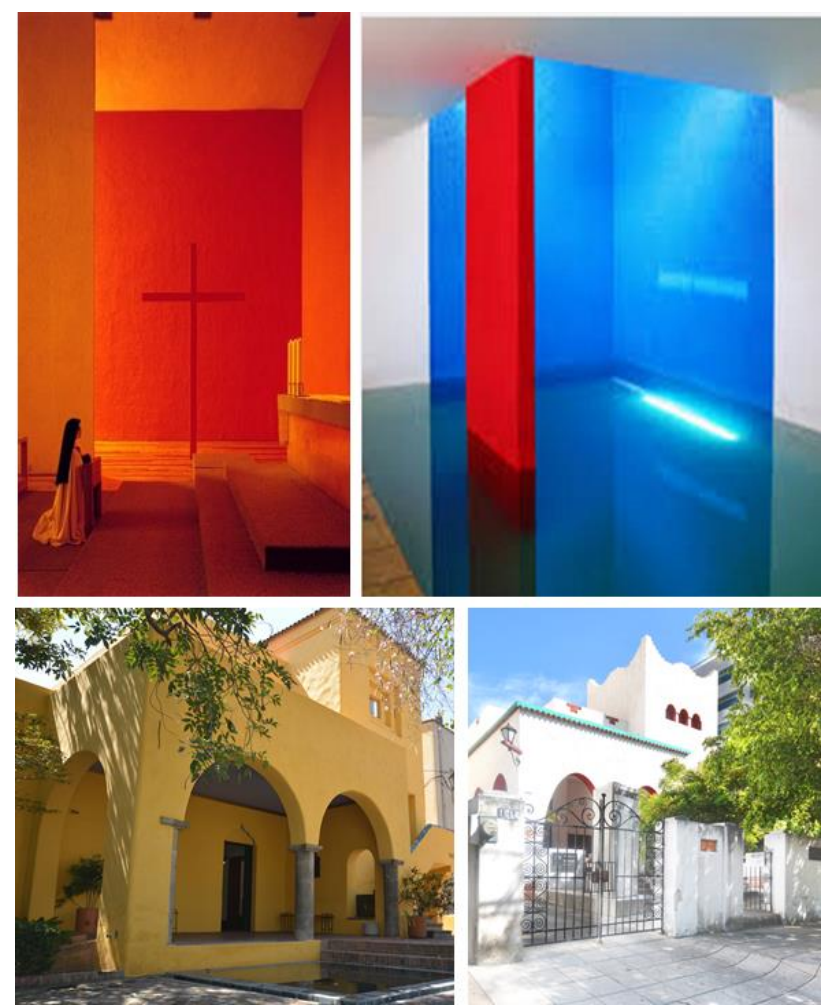

Fig. 1 Examples of the Luis Barragán's Architecural Production. Image source: authors elaboration.

In Jalisco, this new architectural style was an innovative renaissance of the formal national values (Neo-colonial and Neo-indigenous) through modern language and the appropriation of regional scheme and materials (regional architecture)

The architect Luis Barragán was born in Guadalajara in 1902. After graduating as a civil engineer from the Escuela Libre de Ingenieros, he went to Europe in 1925. The journey was particularly significant for his cultural background, as well as his career as an architect. During his stay in Europe, he went to the Exposition des Arts Décoratifs in Paris, where he had the chance to get in contact with some of the most important pioneers of the Modern Movement (such as Le Corbusier, Auguste Perret, etc.). In that occasion, he was also allured by the work of Ferdinand Bac, a writer, an architect and a landscape gardener. Consequently, Barragán began the thorough study of Bac's productions, discovering certain similarities between the mudejar style of the architecture of
North Africa and the materials and forms that recalled the haciendas of his native Jalisco (Del Arenal Pérez, 2010). Moreover, Barragán was exposed with the Arabic architecture during his visit to Córdoba and Granada. Both discoveries of Bac's works and the Arab world, strictly linked to his Guadalajara cultural background, led Barragán to begin a process of translating formal elements into a personal architectural language. The handling of light and shadow, the extensive use of staircase motif, gardens and fountains ${ }^{2}$ became an integral part of his architecture. All these features can be found in the first phase of his works in Guadalajara, where he primarily built private residences for the growing upper middle class.

\subsection{Casa Cristo: significance and brief history}

In 1927, Gustavo R. Cristo, mayor of the city of Guadalajara, commissioned the young architect Luis Barragán to build his house in calle de Pedro Moreno in Guadalajara ${ }^{3}$.

As already mentioned, the style of the house reflects the substantial influences of Barragán's trip to Spain, particularly the architecture of Granada and Córdoba.

It is possible to notice these influences in the moresco style of Casa Cristo, such as the Moorish tower, the entry porch featured by parabolic arches, the silver-gilded door, the textured plaster finishes, the stained glass windows (made from coloured blownglass bottle bases) and the unusual geometry of the back patio.

Furthermore, it is impossible to overlook the connection between Barragán's architecture and the local craftsmanship. Such connotation can easily be observed in many elements, such as the stain glass windows (made in the neighbouring town of Tonalá), the tiles, the mosaics, the zarpeado texture, the adobe walls and the cedar wood capentries.

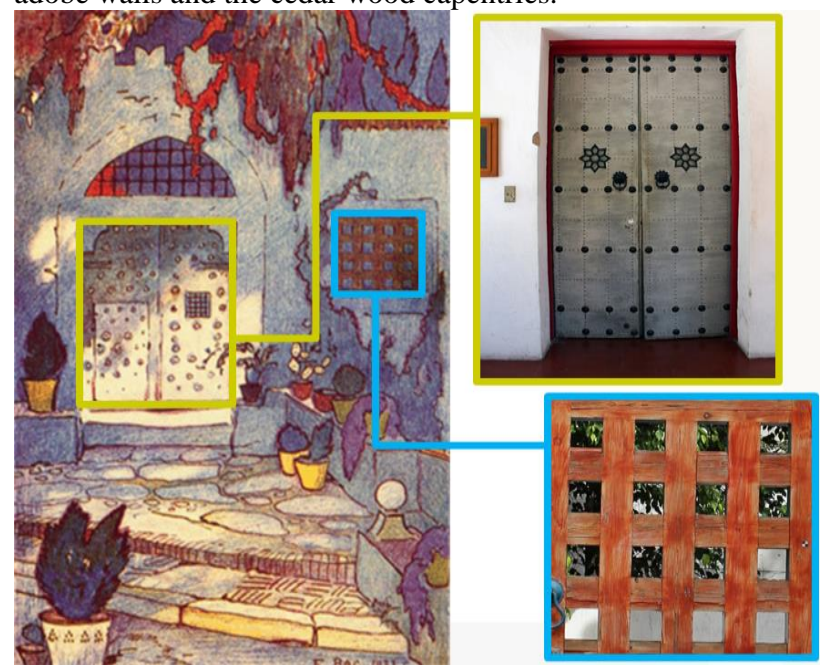

Fig.2 Influences of Ferdinand Bac's illustrations on Luis Barragán architecture of Casa Cristo. Image source: authors elaboration.

All of these features connote Casa Cristo as a regional architecture, despite that it has been strongly influenced by the Jardins enchantès and Les Colombiéres by Ferdinand Bac. It is

\footnotetext{
${ }^{2}$ Indeed, he claimed that water was the music of architecture (Del Arenal Pérez, 2010).

${ }^{3}$ This way of design and build would be known as Escuela Tapatía, which became a signature characterisics of architects like Luis Barragán, Rafael Urzúa and Pedro Castellanos.
} 
possible to notice the similarities in the planning of garden and patios, as well as in the detail design of the house (such as the main entrance door).

In the past years, the house has been modified. This includes the removal of the garden, the replacement of the tiles, the demolition of one of the walls of the dining room and the addition of the loft for office space.

Since 1976, Casa Cristo has been acquired by the Colegio de Arquitectos to serve as its offices (Del Arenal Pérez, 2010). In 2004, it was declared a National Historic Heritage Site (Patrimonio Artístico de la Nación). Currently, there is an ongoing project to transform it into a cultural centre since $2009^{4}$.

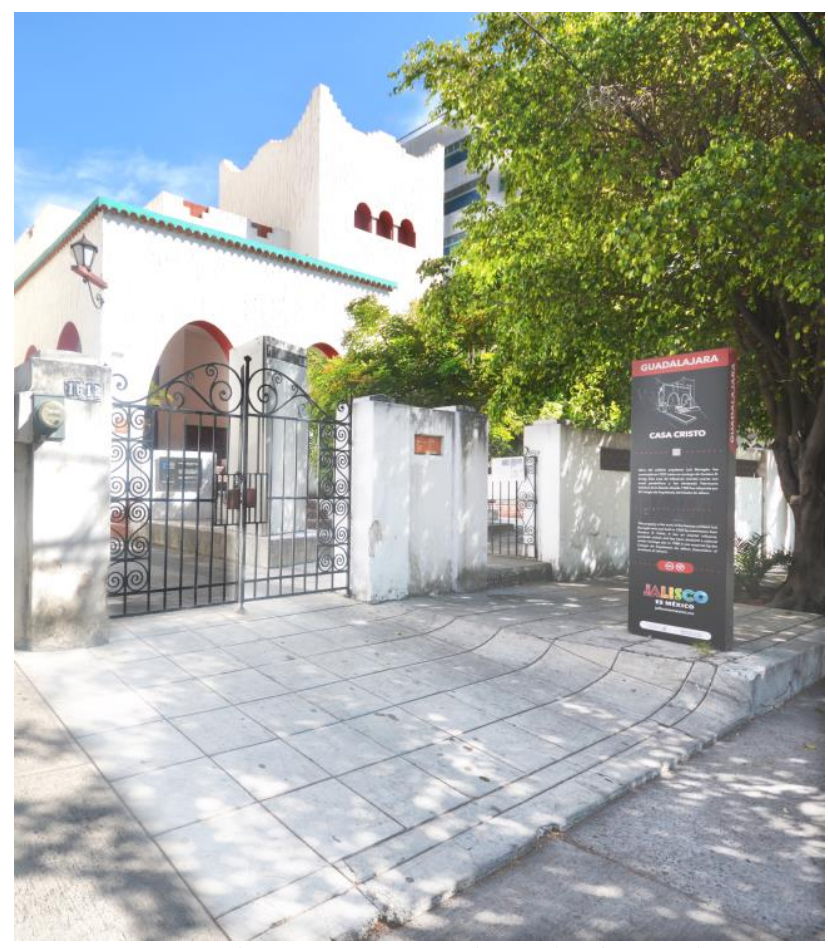

Fig.3 Casa Cristo by Luis Barragán. Photo taken by Davide Mezzino with a Nikon D800 DSLR camera with $50 \mathrm{~mm}$ lens.

\subsection{Course objectives}

The course lasted two weeks. It was structured into 11 days of field work and 3 days of data processing. The goals of the work included:

- Experiencing heritage in Guadalajara and interact with Mexican students and faculties;

- Understanding the role of visual information gathering in recording historic buildings;

- Using recording techniques to quickly capture the current condition of historic buildings;

- Learning about how to integrate information gathered through these techniques into coherent presentations;

- Working in teams throughout the workshop, ultimately completing a graphic and historic record of Casa Cristo;

\footnotetext{
4 Source: Ficha - Pedro Moreno 1612 - Casa Cristo http://revisionesgdl.blogspot.ca/2012/02/ficha-pedro-moreno-1612casa-cristo.html (16 February 2015).
}

- Developing a surveying strategy for other historic buildings in the city.

\section{TRAINING OF ARCHITECTS AND ENGINEERS}

According to the guidelines provided GCI (Normandin, Macdonald, 2013), the education and training approach intended for developing knowledge and skill of potential future professionals in the conservation of modern heritage.

Given the training conditions, students of Carleton and CUAAD employed a group of consolidated surveying equipment for capturing the shape, colour and geometric configuration of Casa Cristo for its eventual rehabilitation and conservation.

The selected toolbox consisted of dimensional and visual tools for capturing the scale and orientation of the building elements, including:

- DSLR cameras for Architectural, Character Defining, Condition and other types of photography;

- REDM Measurements (Using a Total Station, TheoLt and AutoCAD);

- Scaled-rectified Photography and SFM Photogrammetry for mapping ceilings, elevations and cross section elements;

- A spherical Panoramic Photography;

- Hand sketches;

- Distance measuring (DISTO).

\subsection{Training approach}

According to the course objectives, the training approach involved a collective collaboration between the students of the two universities. This approach was driven by the Madrid Document of 2014, developed by the International Scientific Committee on Twentieth-Century Heritage (ISC 20C). According to Article $1^{5}$ of the document, we established a comprehensive profile of the building through different methods $^{6}$ and strategies ${ }^{7}$, in order to assess its significance.

Based on the configuration of the house, the work had been divided between two teams. Team A dealt with the ground floor and the garden area, while Team B dealt with the mezzanine and the first floor. Each team was expected to develop a series of deliverables, including:

- drawings in the scale 1:50 of plans, cross-sections, and elevations;

- condition assessment;

- Identification of character defining elements in each room.

Furthermore, the two teams provided jointly:

- A historical framework of the house and of its urban development,

\footnotetext{
${ }^{5}$ ICOMOS, Approaches for the Conservation of Twentieth-Century Architectural Heritage, Madrid, (2014), p.5.

${ }^{6}$ The methodology should include a comprehensive historic research and proposed an in-depth study of the past and the present heritage policies to support the interpretation of the changing values of the site.

${ }^{7}$ These strategies include identification and assessment of the settings and associated urban landscape (ISC 20C article 1.3) and comparative analysis (ISC 20C article 1.5).
} 
- A territorial framework, including a study of the municipality of Guadalajara, as well as of its metropolitan urban area, mobility, natural elements, and infrastructures.

- A recognition of the existing sustainability featured embedded in the design, in order to develop a conservation strategy that would consider those aspects as a part of the cultural significance of the house.

- A dissemination of the outcomes of the workshop in a public presentation, according to the ISC 20C Article 9 (ICOMOS, 2014).

All the data were used to produce a 3D semantic model in the BIM environment using Autodesk Revit 2014.

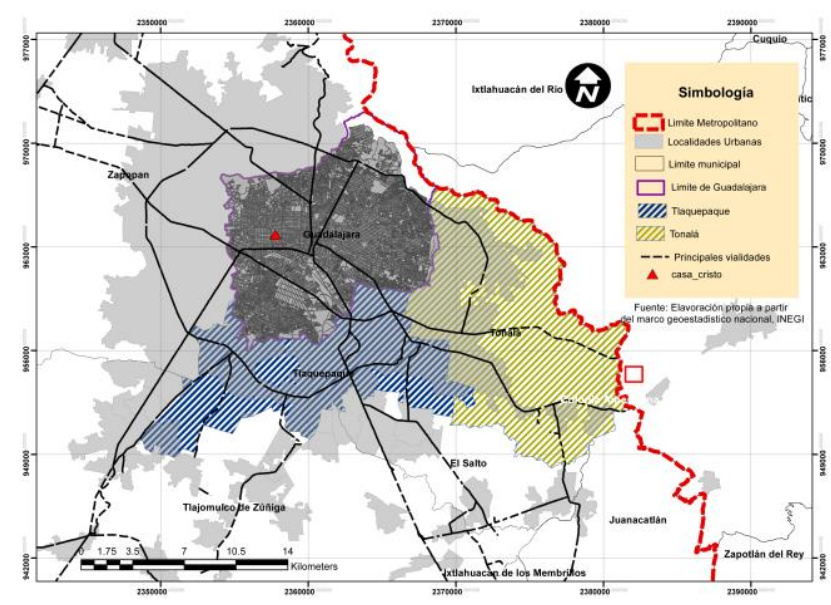

Fig.4 Territorial framework presenting the municipality of

Guadalajara, its metropolitan area and the towns that had a connection with the construction of the Casa Cristo. Map elaborated in ArchGIS verison 9.3.

In order to stimulate the cultural exchange, each team was composed of students from both universities. Within each team, all the members had the opportunity to use and learn about different documentation techniques. Each team organized itself into four subgroups, specifically dealing with:

- Total station survey, field notes and sketches;

- Photogrammetry;

- 2-dimensional drawing production;

- Site digital photography portfolio, including panoramic photographs.

The work was fieldwork based, supervised by the professors of both universities. The final outputs had been presented by representatives of each team, in a public presentation attended by the faculties of CUAAD and local authorities, including the president del Colegio de Arquitecots de Estado de Jalisco and the director of Museo de la Ciudad.

\subsection{Documentation components}

The documentation project included the elaboration of the following components:

- Building Characterization Sheet;

- Report on documentation strategy and results;

- Preliminary Visual Condition Report;

- $\quad$ Field notes and Sketches;

- Measured drawings;

- Site plan;
- Floor plans;

- Cross sections;

- Elevations;

- Details;

- 3D models:

- Digital Photographic Portfolio (DPP);

- Record Photography;

- Panoramic Photography.

\section{RECORDING STRATEGY}

\subsection{Surveying toolbox specifications}

The digital recording of the Casa Cristo was carried out with the help of several surveying instruments, among them, Total Stations equipped with Electronic Distance Measurement (EDM) and connected to a tablet PCs running AutoCAD were employed. The measurements collected by the EDMs were translated into AutoCAD commands using an off-the-shelf available software called TheoLT. Furthermore, Distance measuring (DISTO) was also used to compute distance between straight surfaces. Photogrammetric techniques and rectified photography were employed for elements that are difficult to survey by Total Station, such as windows, doors and gates.

\subsubsection{List of equipment}

The selection of the documentation techniques was based upon the availability of technology. The equipment used included:

- Leica Geosystems Total Station TS11, with a distance accuracy of $2 \mathrm{~mm}$ and angular $2 \mathrm{ppm}$ for linework;

- Leica Geosystems Total Station TS06, with a distance accuracy of $2 \mathrm{~mm}$ and angular $2 \mathrm{ppm}$;

- Digital Photogrammetry using high-resolution Nikon D800 DSLR camera with 36 MP.

\subsection{Surveying network: Setting up a reliable coordinate system}

The EDM Total Stations were used to support the photogrammetric record and the survey of the individual spaces (plans, elevations and sections), by calculating a survey network of the interior and exterior perimeter of the building.

The network was closed, verified and adjusted using traversing calculations. With the traverse in place, the network branched out into smaller rooms from the main survey network.

The two teams were working with the surveyed targets distributed inside and outside of the house.

By using a minimum of three targets per room, the rooms were attached together via clusters of smaller surveys, which were grouped and then tied back to the main survey network. Each new room was established by resection from the previous room. Once in a new room, the network of targets was surveyed. 


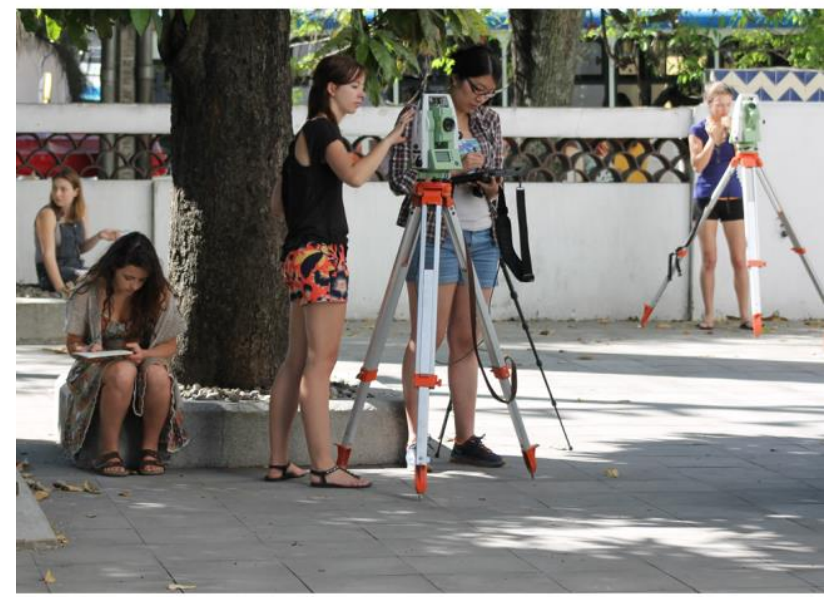

Fig.5 Surveying phase working with the surveyed targets distributed outside the house. Photo's author: Mario Santana Quintero.

Then an outline of the walls of the room was drawn approximately 1.5 meters from the floor. The lines in AutoCAD were divided into different layers, such as windows, wall section, projected lines, etc. Features of the room, such as stairs, floor height elevations, changes in grade, finishes and openings were also measured from the position of the Total Station.

One of the advantages of drawing directly in AutoCAD from the Total Station was the ability to immediately visualize the collected information. This methodology also ensured the degree of accuracy achieved by Total Station recording translated directly into the drawings.

\subsection{Recording the Building's Exterior and Interior}

The same techniques had been used for recording the exterior and the interior part of the building. Photogrammetric technique had been used for the exterior of the Casa Cristo. Due to the consistent work flow, it had been possible to use the main survey network for both outdoor and indoor parts of the house.

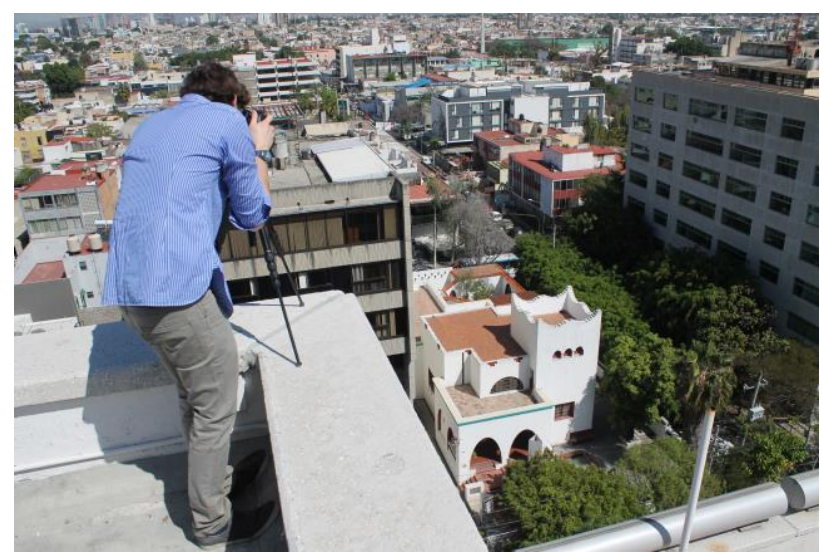

Fig.6 Photos capturing phase of the exterior of Casa Cristo. Photo's author: Kathleen Chin.

\subsection{Field Notes and Sketches}

Sketches had been used primarily during the first phase to produce reference key plans for the location and point ID of the EDM targets and Total Station. Hand drawings have been used along all the field work process to report the information of the building details coming from the hand measurements.

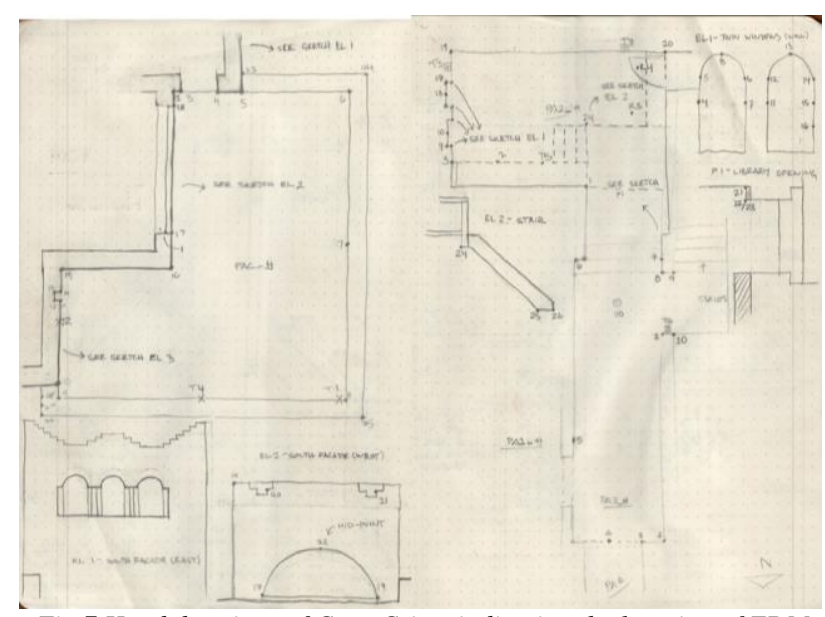

Fig.7 Hand drawings of Casa Cristo indicating the location of EDM targets, architectural details, measurments and generic field notes. Hand drawings' author: Sabina Barrett-Ryan.

\subsection{Total Station survey}

Total station had been an efficient technique to learn within the short time frame of this workshop. Two different Total Sations were used: the Leica Geosystems Total Station TS11 and Leica Geosystems Total Station TS06.

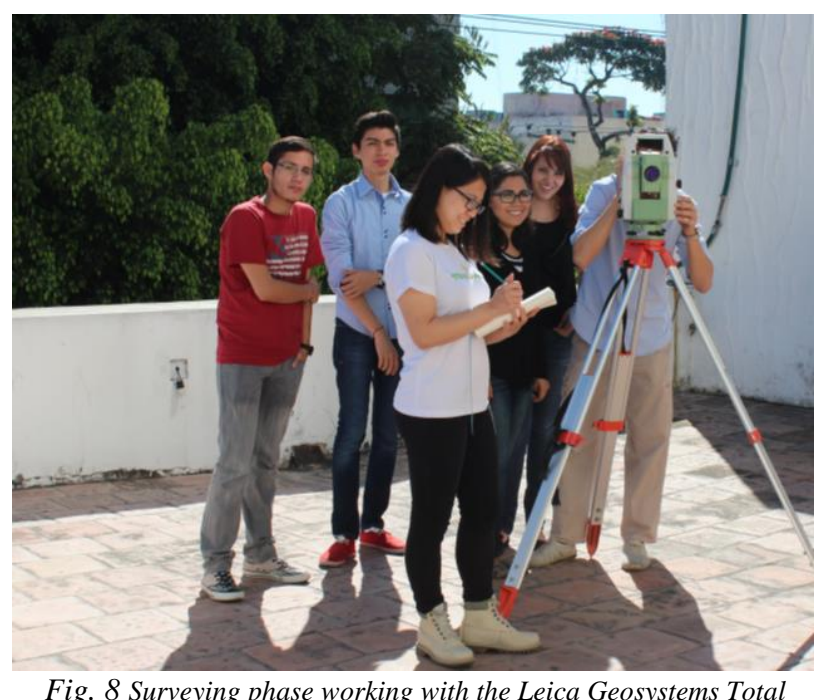

Fig. 8 Surveying phase working with the Leica Geosystems Total Station TS11. Photo's author: Mario Santana Quintero.

\subsection{Photogrammetry}

Photogrammetry had been used to improve the efficiency and the accuracy of the output. Once a completed traverse network had been produced by the Total Station, it was possible to use Photogrammetry to complement the survey. Photogrammetry was also useful in creating multiple drawing types, including orthographical photos for the drawings of building elevations. 


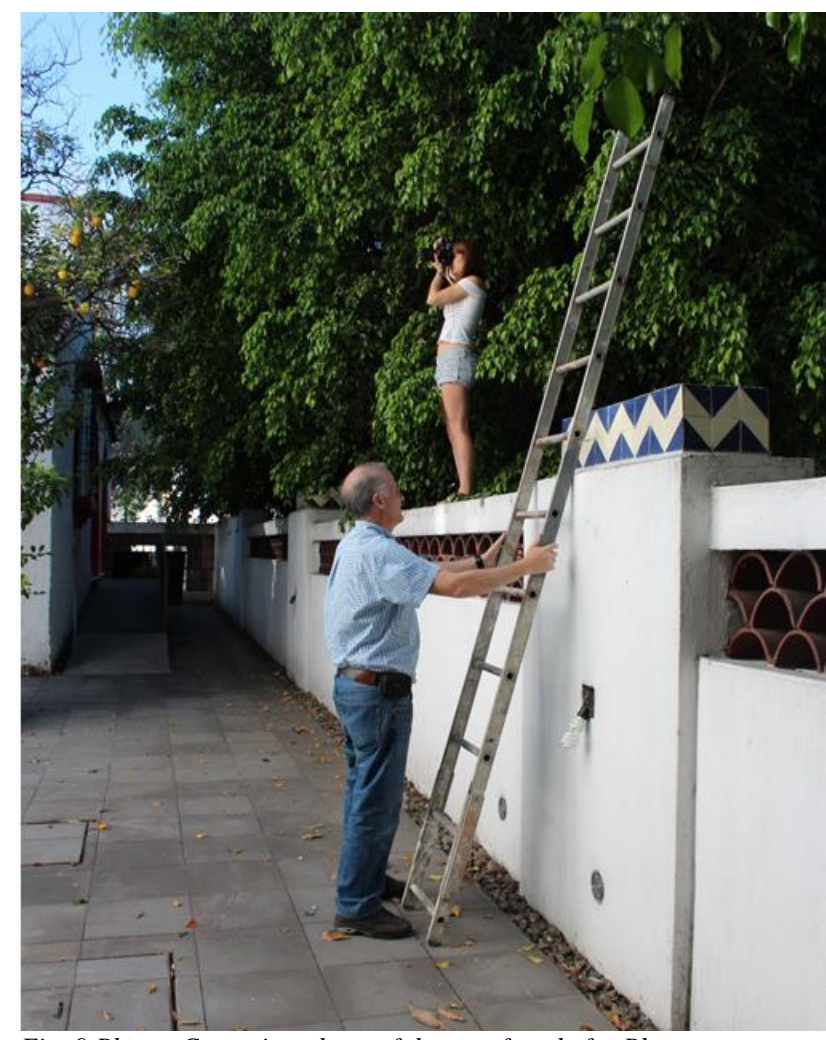

Fig. 9 Photos Capturing phase of the east façade for Photogrammetry. Photo's author: Joel Becker

Photos of the south and east elevations were taken according to the photogrammetric rule ( $3 \times 3)$, established by CIPA (ICOMOS CIPA, 2013), using photogrammetric strips with $60-80 \%$ of overlap. The photos were taken at an appropriate scale in order to capture the details of the structure, given that the drawing set produced was at 1:50 scale. The photos were referenced to the Total Station data and the project coordinate system using the targets on the elevations captured in the same photos.

Photogrammetry models were created using the PhotoScan software. The model was opened in Autodesk Recap, and then exported into a compatible format into Autodesk AutoCAD, where the model was traced in order to produce line drawings. This approach had been replicated for both south and east elevations, as well as the roof plan.

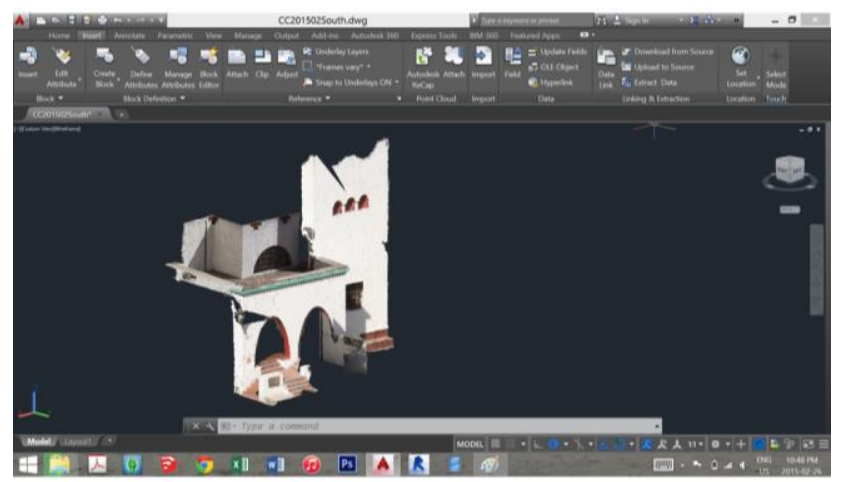

Fig.10 Screenshot of the Photogrammetric model of the south façade imported into AutoCAD 2014.

\subsection{Two-dimensional Drawing Production}

The final drawing production was a combination of data produced from hand measurements, survey and Photogrammetry. The drawings produced in TheoLt were refined in AutoCAD with the support of hand measurements and photographs. The final outputs presented an accurate representation of the site.

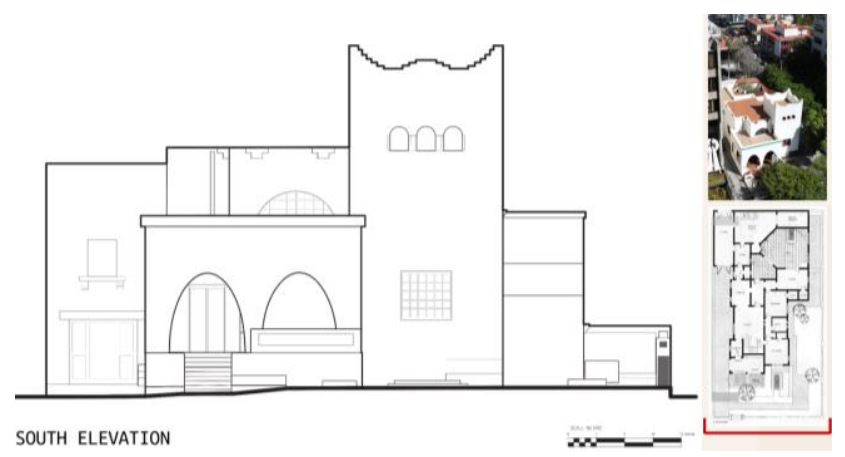

Fig. 11 South elevation of Casa Cristo in scale 1:50. Example of the 2dimensional drawings produced.

\subsection{Record Photography}

During the field work, record photographs were taken. These photographs were used to support the preparation of the twodimensional drawings, showing the drawing production group additional details of rooms surveyed. A photo key plan was prepared to indicate the exact location and the orientation of the photographs.

Furthermore, the photograph site portfolio included character defining elements of both interior and exterior areas, as well as a condition assessment of the building. All these photographs were reference in a key plan, in order to produce an accurate analysis of the significance and condition of the building.

\subsection{Panoramic Photography}

A set of full spherical panoramic photographs of some selected interior and exterior locations was provided. These photographs gave an additional comprehensive visual understanding of the spatial context.

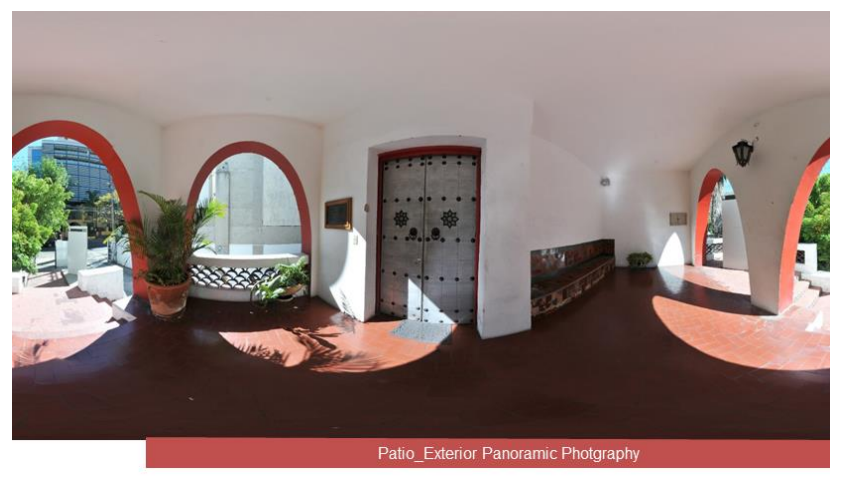

Fig. 12 Panoramic photography of the exterior front patio. Author: Mario Santana Quintero.

The panoramas were prepared by stitching twelve overlapping images for a complete coverage of $360^{\circ}$ of the captured scene (eight horizontal and two bottom and top views). The images were taken using a Nikon D300 DSLR camera (12.3 megapixel DX format CMOS sensor) equipped with a fisheye Nikkor lens of $10.5 \mathrm{~mm}$ that covers a field of view of approximately $180^{\circ}$ diagonals. The taken images were then processed in PTGui Prov9.0 to merge the twelve photos in a panoramic one. 


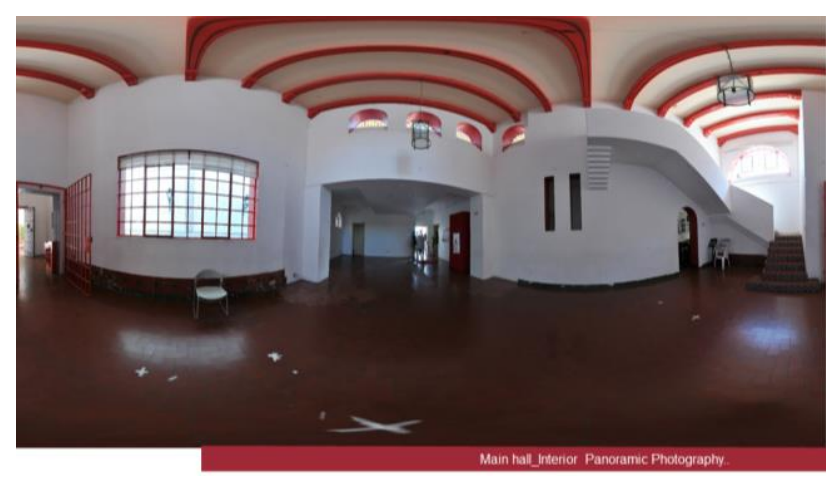

Fig.13 Panoramic photography of the interior main hall. Author: Mario Santana Quintero.

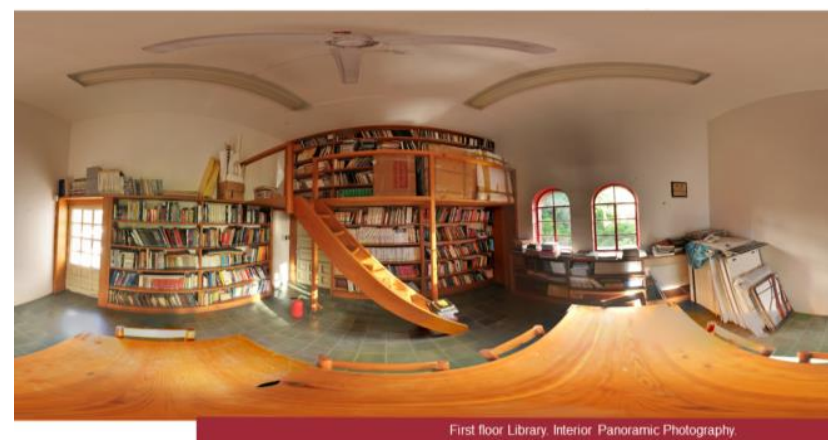

Fig. 14 Panoramic photography of the interior library on the first floor. Authors: Adam Weigert and U Cheng Vong.

CONCLUSIONS

This documentation project aimed at identifying the tangible and intangible elements that characterized the work of Luis Barragán. The scope of the study was not limited to the building itself, but also extended to its territorial context, including the city of Guadalajara and the surrounding villages.

The close connection between Barragan's architecture and the local craftsmanship is demonstrated through architectural details throughout the house, such as handcrafted stained glass windows and ceramic, produced by reputable 'know how' of the nearby villages of Tonalà and Tlaquepaque.

Aside from the tangible characteristics of Casa Cristo, the documentation project also underlined the intangible connotations of the building, including:

- Influence from the European architectural culture and form the Ferdinand Bac's production;

- Connections with the Arabic architecture, particularly the use of water in the design (that became one the recurring elements of his architectural production);

- Distinctive expression of the colonial architectural language, such as the corner lamp and the extensive use of the ceramic.

Despite their tangible nature, all the identified elements, according to a previous in depth historical analysis, are representatives of important meanings and values to understand Barragán production as well as his historical-cultural and social context. Both tangible and intangible aspects of the house were documented in order to provide a solid foundation for the eventual conservation and rehabilitation of the site. The comprehensive recording of the current state of the building ensures the proper preservation of the authenticity and unique characteristics of this outstanding example of modern heritage. On a final note, this workshop was intended to create a systematic documentation strategy that can be used for the conservation of modern heritage.

\section{FURTHER RESEARCH}

The developed documentation project is the first step of the conservation of Casa Cristo. According to the outputs of the workshop, some recommendations for the long term monitoring and future rehabilitation of the site were made. These recommendations included specifications about material compatibility, repairing techniques and preservation of the architectural integrity.

According to the outputs, further research could be conducted in the following areas:

- Conservation, establishing a Conservation Plan of a preventive preservation for the constant monitoring and maintenance of the site;

- Sustainability, developing in-depth study on the bioclimatic architecture features of the house;

- History and sociology, identifying the intangible values in order to orient the rehabilitation process, safeguarding the authenticity of the house and promoting the heritage engagement;

- Policy, elaborating regional heritage charters and developing site-specific conservation declarations through collaboration between the responsible planning and heritage authorities (ICOMOS, 2014).

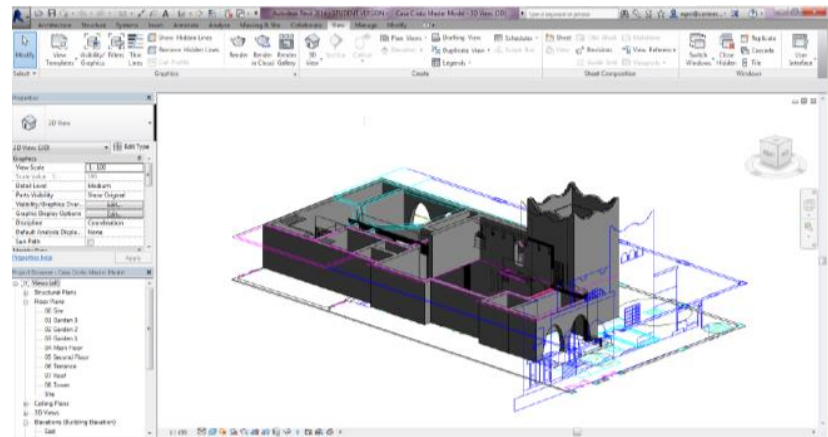

Fig.15 Development phase of the BIM model based on the acquired data. Author: Wei Yi Pei.

All these aspects could be integrated within a 3D semantic model in a BIM environment. This model is capable of recording and managing the different variables and features (tangible and intangible) of the house for its conservation for the present and future generation.

\section{ACKNOWLEDGEMENTS}

This project would not be possible without the support of the faculty of the CUAAD: Flores Gallo Ernesto, Del Rio Lopez Maria Dolores; the Presidente del Colegio de Arquitecots del Estado de Jalisco, A.C. Gonzales Castellanos Enrique Javier; the director of the Museo de la Ciudad Del Arenal Pérez Mónica and her assistant Zaragoza Zaira; Chable Natalia and the architect Reyes Rodriguez Ramon. Furthermore, the authors would like to thank the excellent contributions of the student from both universities: Natalia Paulina Sánchez Aparicio, Alejandro García García, Joana Reneé Hernández Soto, José Antonio Maestro, Paul Ivan Guzmán Gutiérrez, Yolanda 
Bautista Galindo, Ana Gabriela Arellano Rosales, María Fernanda Foubert Lara, Joel Antonio Patiño Rodríguez, Omar Guillermo García Rivas, Aida Mariana Flores Ontiveros, Daniel Arceo Gutiérrez, Alfredo González Flores, Chloe Weiyi Pei, U Cheng Vong, Celine Boulanger, Aviva Shapiro, Adam Weigert, Joel Becker, Natalie Waddington, Sabina Barrett-Ryan, Kathleen Chin, Isis Bennet, Chelsea Jacobs and Davide Mezzino.

\section{REFERENCES}

Buendìa Jùlves J. M., Eguiarte G., Palomar J., 2001. Luis Barragán. Editorial RM, S.A. DE C.V., México, D.F.

Del Arenal Pérez M., 2010. Guadalajara de Alarifes, Catrines y bicicleteros / builders, dandies and cyclists. Coloristas y Asociados, Leon.

ICOMOS, Approaches for the Conservation of TwentiethCentury Architectural Heritage, Madrid, (2014), p.5.

ICOMOS, Approaches for the Conservation of TwentiethCentury Architectural Heritage, Madrid, (2014), p.9.

Letellier R., Schmid W., LeBlanc F., 2007. Recording, Documentation, and Information Management for the Conservation of Heritage Places. The Getty Conservation Institute, Los Angeles.

Macdonald S., Normandin K. C., Kindred B., 2013. Conservation of Modern Architecture. Routledge, London.

Maisterra N., 2002. Luis Barragán: Obra en Guadalajara. Nemesio Maisterra Cruz, México, D.F.

Normandin K., Macdonald S., 2013. A Colloquium to Advance the Practice of Conserving Modern Heritage. The Getty Center, Los Angeles,

\section{Web site references}

Ficha - Pedro Moreno 1612 - Casa Cristo

http://revisionesgdl.blogspot.ca/2012/02/ficha-pedro-moreno-

1612-casa-cristo.html (16 February 2015)

Luis Barragán y su obra

http://revisionesgdl.blogspot.mx/2012/05/perfiles-luis-

Barragán-su-obra-en.html (27 February 2015)

The CIPA $3 \times 3$ rules

http://cipa.icomos.org/fileadmin/template/pdf/3x3-

23_10_2013.pdf ( 14 March 2015) 